\title{
Visual performance in giant cell arteritis (temporal arteritis) after 1 year of therapy
} Mark J Kupersmith, Regina Langer, Hal Mitnick, Robert Spiera, Harry Spiera,
Marjorie Richmond, Stephen Paget

\begin{abstract}
Aims-To determine if patients with giant cell arteritis (GCA) treated with corticosteroids develop delayed visual loss or drug related ocular complications. Methods-In a multicentre prospective study patients with GCA (using precise diagnostic criteria) had ophthalmic evaluations at predetermined intervals up to 1 year. The dose of corticosteroid was determined by treating physicians, often outside the study, with the daily dose reduced to the equivalent of 30-40 $\mathrm{mg}$ of prednisone within 5 weeks. Subsequently, treatment guidelines suggested that the dose be reduced as tolerated or the patient was withdrawn from steroids in a period not less than 6 months.
\end{abstract}

Results-At presentation, of the 22 patients enrolled, seven patients had nine eyes with ischaemic injury. Four eyes had improved visual acuity by two lines or more within 1 month of starting corticosteroids. No patients developed late visual loss as the steroid dose was reduced. At 1 year the visual acuity, contrast sensitivity, colour vision, and threshold perimetry were not significantly different from the 4-5 week determinations. At 1 year, there were no significant cataractous or glaucomatous changes. At 2 months, there was no difference in systemic complications between patients who received conventional dose (60-80 $\mathrm{mg}$ per day) or very high doses (200-1000 mg per day) of corticosteroids at the start or early in the course.

Conclusions-Patients with GCA related visual loss can improve with treatment. Corticosteroids with starting doses of 60-1000 mg per day, with reduction to daily doses of $40-50 \mathbf{m g}$ per day given for 4-6 weeks, and gradual dose reduction thereafter, as clinically permitted, did not result in delayed visual loss. There were no significant drug related ophthalmic complications.

(Br f Ophthalmol 1999;83:796-801)

Giant cell arteritis (GCA) is a systemic illness which affects men and women older than 55 years of age (more often older than 65) which can cause severe visual loss in affected individuals unless treated early. The inflammation of the ophthalmic arterial branches leads to ischaemic disease of the orbit with profound optic neuropathy, retinal and choroidal infarction, and less commonly, ocular movement limitation. ${ }^{1-4}$ Corticosteroid treatment must be started as soon as the diagnosis is suspected since in $10 \%$ to $33 \%$ of untreated patients, the second eye will lose vision within 1 day to 3 weeks. ${ }^{5}$ Unfortunately, the required long term (6-24 months) treatment with corticosteroids often leads to severe systemic complications such as osteoporosis, gastric ulcer, diabetes, high blood pressure, immunosuppression, depression, weight gain, ${ }^{67}$ and ocular complications such as cataract and glaucoma. ${ }^{8-11}$ Preliminary studies have suggested that an antiinflammatory drug, methotrexate may be beneficial for GCA because its use permits lower doses of corticosteroids to be administered with concomitant reduction in complications. ${ }^{12}$ However, one prospective study using low dose ( $7.5 \mathrm{mg} /$ week $)$ methotrexate showed no benefit on GCA or polymyalgia rheumatica. ${ }^{13}$

We established a clinical trial at three university medical centre rheumatology and neuroophthalmology services to compare conventional corticosteroid therapy with a combination of methotrexate and corticosteroid treatment to address the question of disease control and rate of drug related complications. Difficulties with recruitment precluded sufficient numbers to answer the question whether methotrexate is beneficial but the prospective collection of data has provided some results with respect to the following questions:

(1) Do daily pharmacological doses of corticosteroids given for 1 year cause significant cataract development or elevation of intraocular pressure in the elderly? Can the total cumulative corticosteroid dose be correlated with any ophthalmic complication?

(2) Can corticosteroid therapy improve the vision in an eye with ischaemic injury from GCA?

(3) Does a short term ( $<7$ days) initial daily dose of $200-1000 \mathrm{mg}$ of corticosteroids cause more systemic complications than an initial dose of 40-60 mg?

(4) Do patients with GCA experience visual loss vision at 1 year while on small doses or no corticosteroid?

(5) Do the eyes of patients with GCA have a poorer vision at 1 year compared with the visual performance after 4-6 weeks of treatment?

Methods

Twenty two patients aged over 55 years with GCA who met criteria modified from the American College of Rheumatology ${ }^{14}$ (Table 1) 
Table 1 Criteria for diagnosis of giant cell arteritis (GCA)

(1) Patients must have symptoms suggestive of GCA and a temporal artery biopsy (performed inflammatory cells, disruption of the internal elastic lamina, with or without giant cells, except for (2) or (3).

(2) Patients with acute anterior or posterior ischaemic optic neuropathy with symptoms suggestive of GCA (polymyalgia rheumatica, temporal fossa headache, scalp tenderness, loss of appetite, jaw claudication, tongue claudication, weight loss, night sweats), and ESR $>60 \mathrm{~mm}$ in the first hour (without other cause for elevated ESR - that is, blood dyscrasia, lymphoma, tuberculosis, renal failure) even if negative temporal artery biopsy.

(3) Patients with symptoms suggestive of GCA and pulseless disease with ESR $60 \mathrm{~mm}$ in the first hour using the slit beam slightly wider than the pupil and simply graded as clear or unclear.

All patients received daily corticosteroid therapy (range 40-1000 $\mathrm{mg}$ ) after initial diagnosis. The starting dose was left to the clinical judgment of the referring treating physician. Over 4-6 weeks the daily steroid dose was reduced to the equivalence of 30-40 $\mathrm{mg}$ of prednisone at which time each patient was randomised to receive either methotrexate or placebo in addition to the steroids. Since not all the rheumatologists clinically managing the patients were study investigators, the following regimen for the prednisone therapy was only suggested:

The dose of prednisone was to be gradually decreased by $10 \mathrm{mg} /$ week until $40 \mathrm{mg}$ per day is reached by the end of the first month, then by $5 \mathrm{mg} /$ week until $20 \mathrm{mg}$ per day is attained at the end of the second month. Subsequent tapering should be by $2.5 \mathrm{mg}$ per week until the drug is completely suspended. The prednisone taper should be halted or the dose increased by $5-10 \mathrm{mg}$ /day or more in order to control the symptoms or signs if a relapse occurs. A relapse is defined as recurrence of symptoms of GCA after definite improvement by prednisone, followed by symptom normalisation upon resumption or increase of the prednisone dose. An increase in the erythrocyte sedimentation rate (ESR) alone is not used as the indication for increasing the steroid dose.

After 4-6 weeks of corticosteroids, patients were randomised to either the addition of oral placebo or methotrexate of $10 \mathrm{mg}$ per week. At 1 year, if a remission was achieved, the methotrexate dose was to be reduced by 2.5 $\mathrm{mg} / \mathrm{month}$ until it is completely withdrawn.

All patients received $1500 \mathrm{mg} /$ day of calcium carbonate and $400 \mathrm{IU}$ of vitamin D to prevent osteoporosis, folic acid $1 \mathrm{mg}$ orally each day, a $\mathrm{H}_{2}$ blocking agent or carafate $1 \mathrm{~g}$ daily to prevent gastrointestinal ulceration. No patient received other anti-inflammatory drugs, sulfa drugs, or other immunosuppressive agents. When necessary the appropriate agent was added to control blood pressure, blood glucose, or prevent worsening osteoporosis.

and pattern standard deviation (PSD) $<5 \%$ The visual field data were also scored using the advanced glaucoma intervention study protocol (AGIS score). ${ }^{16}$

The degree of opacification in the lens was measured using a modification of LOCSII. ${ }^{17}{ }^{18}$ Following pupillary dilatation $>5 \mathrm{~mm}$, with tropicamide $1 \%$, the lens was examined and the degree of opacification in the nucleus, cortex, and posterior subcapsular zones was graded. Opacities were defined as being present only if they were visible against the red reflex, otherwise the grade was 0. "Aggregate" opacification was derived by mentally summing the area of the opacities from noncontiguous locations in one zone and determining if the sum was as large as an entire quadrant (grade 2) or just less than the quadrant (grade 1b) or a small, minor cluster (grade 1a). A separate grade was recorded for the cortical and the posterior subcapsular zones. Nuclear opacification was determined

\section{DATA ANALYSIS}

In the patients with visual loss, the visual acuity at presentation was compared with the visual acuity at entry into the study which was after 4-6 weeks of corticosteroid therapy.

The mean and standard deviations were determined for all the visual measures at baseline and at 1 year and Student's test was used to determine significance. For each, visual variable values at baseline were subtracted from the 1 year values. Linear regression analysis was used to demonstrate correlation between total cumulative steroid dose and change in lens, total cumulative steroid dose and change in contrast sensitivity, change in contrast sensitivity and change in MD and PSD, and change in contrast and change in lens. Eyes with synthetic intraocular lens were omitted from lens related analyses (six eyes of four patients). Two eyes of one patient with 


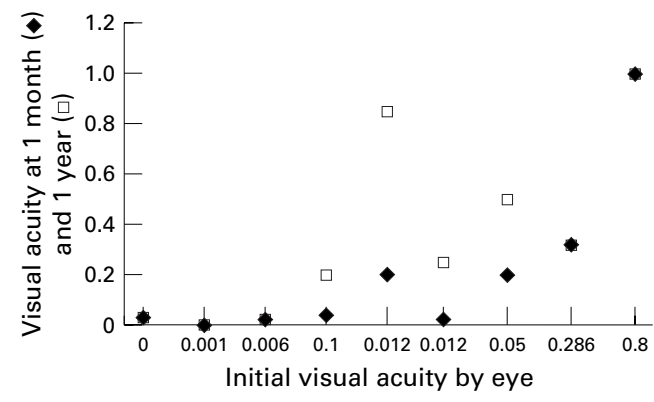

Figure 1 Changes in visual acuity expressed by eye as a decimal value. Recall three eyes in two patients had better pre-entry acuity which deteriorated within 5 days on oral prednisone.

known chronic open angle glaucoma were included in all analyses. One eye (not clinically affected by GCA) of one patient with a large macular scar from childhood was eliminated from all analyses of visual performance. Owing to patient non-compliance, there was no repeat visual field data at 1 year for her two eyes.

\section{Results}

Seven men and 15 women with a mean age 73 years (SD 7 years) were enrolled. The mean ESR was $70 \mathrm{~mm}$ in the first hour (SD $39 \mathrm{~mm}$ ). Histopathological examination revealed a positive temporal artery biopsy in 19 patients and a negative result in three patients. Owing to the nature of referrals to the study by both a neuro-ophthalmologist and rheumatologists and the various modes of clinical presentation, the initial steroid dose was not uniform and patients received daily doses of corticosteroids of 40-1000 mg. The initial daily corticosteroid dose was prednisone $40 \mathrm{mg}$ in two patients, 60 $\mathrm{mg}$ in 14 patients, $80 \mathrm{mg}$ in one patient, $80-120 \mathrm{mg}$ in one patient, $200 \mathrm{mg}$ in three patients, and one patient received methylprednisolone $1000 \mathrm{mg}$ per day. Two patients subsequently were treated with methylprednisolone $1000 \mathrm{mg}$ per day after failing with daily prednisone $60 \mathrm{mg}$ and $100 \mathrm{mg}$.

Seven patients had nine eyes with permanent visual loss (seven eyes with ischaemic optic neuropathy and two with central retinal artery occlusion). Two patients developed visual loss after prednisone was begun; one had both eyes affected after 3 days of $60 \mathrm{mg}$ and the second had one eye affected after $80 \mathrm{mg}$ for 2 days and $120 \mathrm{mg}$ for 2 days. These two patients and a third patient with acute ischaemic optic neuropathy were treated with intravenous methylprednisolone $1000 \mathrm{mg}$ per day. Three other patients with subacute visual loss, untreated for 1 week before diagnosis, were treated with prednisone $200 \mathrm{mg} /$ day. One additional patient with a mild ischaemic optic neuropathy (20/25 acuity and an altitudinal

Table 2 Comparison of mean (SD) baseline and 1 year visual performance for 44 eyes

\begin{tabular}{llll}
\hline & Baseline & 1 Year & p Value \\
\hline Acuity & $0.8(0.46)$ & $0.83(0.39)$ & 0.76 \\
Contrast log units & $1.2(0.54)$ & $1.2(0.58)$ & 0.52 \\
Colour vision & $0.8(0.39)$ & $0.8(0.39)$ & 0.99 \\
Mean deviation & $-8.72(9.36)$ & $-5.89(8.95)$ & 0.38 \\
Pattern standard deviation & $4.44(2.76)$ & $3.76(2.82)$ & 0.36 \\
AGIS score & $6.02(6.03)$ & $5.38(6.51)$ & 0.28 \\
\hline
\end{tabular}

field defect) received $80 \mathrm{mg}$ of prednisone daily. No patient developed visual loss or worsened after 5 days of therapy.

At the entry examination, of the 44 eyes, the intraocular pressure was elevated above $22 \mathrm{~mm}$ $\mathrm{Hg}$ in four eyes, two of which were known to have chronic open angle glaucoma (in one patient without GCA caused visual loss). The eyes in this patient had the same intraocular pressure elevation after starting steroids as before. The other two eyes (in the one patient with bilateral visual loss) had pressures of 25 and $26 \mathrm{~mm} \mathrm{Hg}$ after steroids (not before), which normalised on prophylactic topical $\beta$ blocker ophthalmic drops. Neither of the latter two eyes had any worsening of the visual field or increase in the cup to disc ratio over 1 year.

Compared with the pre-entry evaluation of patients with visual loss, the visual acuity improved two lines or more in four eyes within 1 month of starting treatment (Fig 1). In one patient, who received intravenous methylprednisolone $1000 \mathrm{mg}$ per day for 3 days, the worse of her two affected eyes improved from finger counting (0.012) to $20 / 800$ (0.025), and the second eye improved from 0.286 to 0.317 (not two lines). One patient treated with intravenous methylprednisolone $1000 \mathrm{mg}$ per day for 5 days had an improvement in one eye from no light perception with an amaurotic pupil at presentation to 0.03 at 1 month which was maintained at 1 year. Two patients who received oral prednisone $200 \mathrm{mg}$ per day for 5 days each had one eye improve from 0.05 to 0.2 and 0.012 to 0.2 . A fifth patient, originally thought to have non-arteritic anterior ischaemic optic neuropathy because of the mild visual acuity loss and altitudinal defect, was treated with prednisone $80 \mathrm{mg}$ per day for the first week and improved the visual acuity from 0.8 to 1.0 without a significant change in the visual field.

In general, most eyes of patients, regardless of arteritis related visual loss at the baseline entry examination, did not have a significant change in visual acuity, contrast threshold, mean deviation, or pattern standard deviation of threshold perimetry, AGIS score, or colour vision from baseline to the 1 year evaluation (Table 2, Figs 2 and 3). However, 13 eyes of nine patients were considered normal by AGIS at 1 year in contrast with only six eyes in five patients at baseline. For MD, 18 eyes were improved (mean change 4.7 (SD 2.6)), 12 eyes were worse (mean change $-3.3(2.0)$ ) and 11 were unchanged. For PSD, 12 eyes were improved (mean change -3.4 (1.6)), 10 eyes were worse (mean change 2.8 (1.2)), and 19 eyes were unchanged. There was no correlation with change in the contrast threshold or the change in MD or PSD (Table 3).

Changes in the cortical zone or the posterior subcapsular zone occurred in 15 of the 38 eyes with their own lens. Cortical zone changes of one grade and two grades were noted in six and two eyes, respectively. Posterior subcapsular changes of one grade were noted in 11 eyes and none had two grade changes. There was no correlation with the change in lens and change in contrast threshold, MD, or PSD (Table 3). 


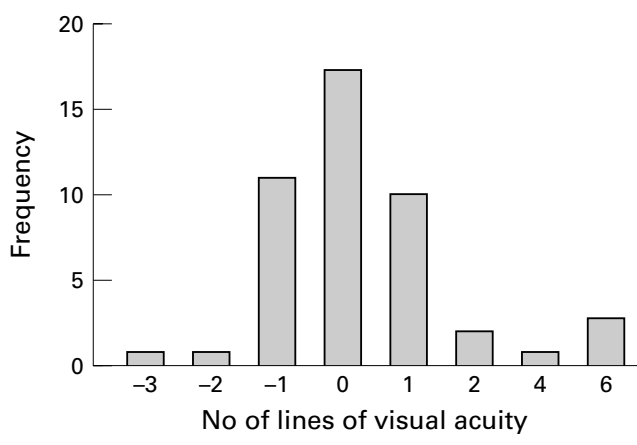

Figure 2 Changes in visual acuity at 1 year. Positive numbers indicate improvement and negative numbers, worsening. Frequency is expressed as number of eyes.

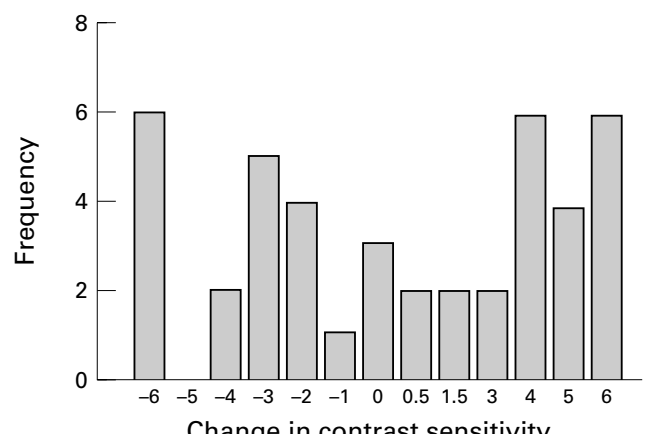

Figure 3 Change in contrast at 1 year from baseline expressed in log units $\times 10^{-1}$. Positive numbers indicate improvement and negative numbers, worsening. Frequency is expressed as number of eyes.

The total cumulative dose of corticosteroid did not correlate with the change in either lens measurement (Table 3).

The seven eyes with contrast sensitivity of $0.5 \log$ units or less were more closely inspected to look for a possible subgroup of cataract development. Of these seven eyes, four had lens changes, one with minor (1a) cortical zone and one with minor (1b) posterior subcapsular zone changes. Two eyes had cortical changes less than one quadrant (1b). In these seven eyes, the MD improved in four, worsened in two, and was unchanged in one eye. The PSD improved in two and was unchanged in five eyes. Thus, there were no consistent data suggestive of visually significant cataract development.

Patients treated with $1000 \mathrm{mg}$ of corticosteroid daily did not have higher total cumulative doses at 1 year than those patients initially treated with $40-60 \mathrm{mg}$ daily. The mean cumulative dose of corticosteroid (methylprednisolone for intravenous and prednisone for oral use) was $5906 \mathrm{mg}$ (SD $1955 \mathrm{mg}$ ). The total dose of prednisone was similar for patients with (5825 $\mathrm{mg}(2570)$ ) and without visual loss (5938 mg (1644), $\mathrm{p}=0.9$ ). There

Table 3 Comparison of change in visual performance measures from baseline to 1 year for 44 eyes $^{*}$
Linear regression coefficient

Change contrast and mean deviation

Change contrast and pattern standard deviation

Change contrast and cortical zone

Change contrast and posterior subcapsular zone

Change in cortical zone and cumulative steroid dose

Change in posterior subcapsular zone and cumulative steroid dose
0.01

0.01

0.02
0.08

0.008

0.02
^All eyes except as noted in methods. was no difference in the cumulative steroid dose between the 12 patients who received methotrexate (6184 $\mathrm{mg}$ (2048)) and the 10 patients who received placebo (5436 $\mathrm{mg}$ (1600), $\mathrm{p}=0.39$ ).

Corticosteroid associated systemic complications, none permanent, during the first 2 months of therapy required intervention in seven patients. Three patients required oral hypoglycaemic agents to lower elevated blood glucose and six others had elevation in blood glucose requiring no medication. No patient developed new systemic hypertension. One patient developed pneumonia requiring hospitalisation. One patient became psychotic on oral prednisone $40-60 \mathrm{mg}$ several weeks after an uncomplicated initial intravenous methylprednisolone $1000 \mathrm{mg}$ daily. One patient had mild euphoric personality changes. Two patients had a focal herpes zoster rash treated with an oral antiviral agent. After the first 2 months, there were no additional cases of hyperglycaemia or significant infection. There were no pathological fractures during the first 2 months of therapy. At 1 year there were two vertebral fractures and no hip fractures. As expected, there were numerous minor symptoms such as weight gain, water retention, acne, gastrointestinal discomfort, thin skin, hair thinning, hirsutism, and mood change.

\section{Discussion}

As described in earlier studies, patients with GCA associated visual loss can recover with corticosteroid treatment. In our patients, the improvement in acuity was noted within weeks of starting therapy and never after 1 month. One patient with acute (less than 2 hours) loss of vision and no light perception in an eye with an amaurotic pupil improved after receiving methylprednisolone $1000 \mathrm{mg}$ daily. Of the four eyes that improved two lines or more on the visual acuity chart, only one received methylprednisolone $1000 \mathrm{mg} /$ day. The others were treated with oral prednisone $200 \mathrm{mg}$ daily.

All measures of visual performance after 1 year of therapy in patients with giant cell arteritis were fairly stable when compared with the measurements taken at approximately 4-5 weeks after initiating corticosteroid therapy (entry point into treatment trial). The more sensitive measures of vision, contrast sensitivity and threshold perimetry, showed no significant pattern of change and, in fact, in many eyes the improvement or worsening on one test was not paralleled by an improved result on another visual performance measure. However, because of fixation losses and false negative and positive errors, the results of threshold perimetry were probably less reliable than the other visual studies.

Patients can be given corticosteroids 200$1000 \mathrm{mg}$ per day for a week without severe long term ocular or short term unmanageable systemic complications. Prednisone $40-80 \mathrm{mg}$ daily for the next 3-5 weeks followed by a judicious dose reduction over months also appeared to be tolerated relatively well. In contrast, the high rate of complications in other studies probably resulted from protracted use 
of high dose steroids. ${ }^{7}$ The fact that in our study gradual reduction to $40 \mathrm{mg}$ daily after 4-5 weeks was not associated with the onset of new visual loss suggests it is probably unnecessary to maintain patients on larger doses of prednisone for months. We are in the process of determining whether initial treatment with a short course of corticosteroids $200-1000 \mathrm{mg}$ per day causes more late systemic complications such as hypertension, diabetes, osteoporosis, and pathological bone fractures than initial daily doses of $40-80 \mathrm{mg}$.

Although it appears that megadose (1000 $\mathrm{mg}$ ) intravenous or $200 \mathrm{mg}$ orally can be taken by the elderly without more complications than conventional lower dose corticosteroid, the optimal dose to possibly improve vision or prevent visual loss in the second eye has not been established by this or any other study. Anecdotal cases of visual loss developing after 1 week of up to prednisone $200 \mathrm{mg}$ daily which reversed with $1000 \mathrm{mg}$ daily have been described. ${ }^{19}$ Since treating patients with high doses of corticosteroid for the first 1-2 weeks seems unlikely to increase the incidence of complications, until it is established that lower doses are as effective, higher dose (200-1000 $\mathrm{mg}$ per day) therapy seems warranted in patients with visual loss and maybe even in those who have not experienced neurological or ophthalmological symptoms. There appear to be few reasons not to use $200 \mathrm{mg}$ or more per day in cases with acute visual loss or in cases that are worsening while on conventional moderately high dose oral steroids $(60-80 \mathrm{mg})$. Afterwards, unless there is a definite clinical flare up of GCA, the dose of corticosteroid should be reduced to the equivalent of $40 \mathrm{mg}$ of prednisone within 4-6 weeks. Lowering the daily steroid dose thereafter as clinically tolerated appears to be prudent in that it appeared to be the reason for the reduced number of permanent or long term complications in this study.

We had two patients who developed loss of vision while receiving prednisone $60 \mathrm{mg}$ and 80-120 mg per day, with both showing deterioration in less than 1 week into treatment. Numerous reports have documented the acute loss of vision in the first or second eye during the first 2 weeks of oral prednisone $40-100 \mathrm{mg}$ per day ${ }^{20-27}$ and even in a patient treated with intravenous prednisone $1000 \mathrm{mg}$ daily. ${ }^{28}$ However, visual loss is more likely to occur in patients given prednisone in daily doses of less than $30 \mathrm{mg}$, such as are typically used for polymyalgia rheumatica. ${ }^{6}{ }^{29} 30$ Patients have also been reported to lose vision if the prednisone is reduced too quickly, usually to less than $30 \mathrm{mg}$ within 4 weeks $^{31}$ or to $10 \mathrm{mg}$ within 2 months. ${ }^{33}$

In contrast, delayed visual loss following treatment for months with $20-30 \mathrm{mg}$ per day of prednisone after initial therapy using $60-80 \mathrm{mg}$ per day is rare. We had no patients who developed ischaemic visual loss after 1 or more months of treatment. Although repeat temporal artery biopsy 6 months to up to 9 years $^{26}{ }^{34}$ after corticosteroid treatment, may show continued or recurrent inflammatory changes, the risk of visual loss in these patients is unknown. Because the population affected by GCA is also at risk for non-arteritic vascular occlusive disease, reports of central retinal artery occlusion or anterior ischaemic optic neuropathy occurring many months to years after what would be considered adequate treatment may not actually represent recurrence of arteritis. There are numerous reports which contain cases of ischaemic visual loss which appear to be non-arteritic. ${ }^{21} 272935$ Unfortunately, some articles have poor documentation of the visual system findings that developed after months of treatment so no definite conclusion can be drawn from many of these reports. ${ }^{36} 37 \mathrm{We}$ could find three cases with definite GCA caused delayed visual loss, two following 2 months $^{24}{ }^{38}$ and one after 5 months of therapy, ${ }^{23}$ but none after 1 or more years of treatment with doses of steroids considered adequate for GCA by most North American rheumatologists.

Lastly, the results in this small study differ from the results of earlier larger studies of longer duration that found significant ocular complications of chronic corticosteroid use. Glaucoma has been reported to develop in approximately $8 \%$ of patients on long term systemic therapy, ${ }^{8}$ although there is no clear correlation with dose or duration of therapy. ${ }^{9} 10$ The new onset of elevation of intraocular pressure occurred in $4 \%$ of patients (one case) without the development of glaucomatous cupping. Cataract formation, usually bilateral, is associated with dose and duration of the systemic corticosteroid therapy. ${ }^{9}$ The opacification typically begins in the posterior subcapsular region and eventually spreads to the cortex. After 1 year of systemic corticosteroids in our patients older than 55 years of age, significant cataractous changes or visual loss from lens opacification, determined by a reduction in visual acuity or contrast sensitivity, or worsening of the mean deviation of threshold perimetry, were not found. This was not unexpected since the prevalence of cataractous change, particularly posterior subcapsular opacification, appears to increase with duration longer than 1 year, typically longer than 5 years, of systemic corticosteroid use. ${ }^{39}$

Supported by the AARP Andrus Foundation and New York Arthritis Foundation.

1 Wagener HP, Hollenhorst RW. Ocular lesions of temporal arteritis. Am $\mathcal{F}$ Ophthalmol 1958;45:617-30.

2 Russell RWR. Giant-cell arteritis: a review of 35 cases. $Q \mathcal{F}$ Med 1959;28:471-8.

3 Henkind P, Charles NC, Pearson J. Histopathology of ischemic optic neuropathy. Am F Ophthalmol 1970;69:7890

4 Wilkinson IMS, Russell R, Ross W. Arteries of the head and neck in giant cell arteritis. a pathological study to show the pattern of arterial involvement. Arch Neurol 1972;27:378-9 5 Grahm E, Holland A, Avery A, et al. Prognosis in giant cell arteritis. BMF 1981;282:269-71.

6 Delecoeuillerie D, Jolly P, Cohen de Lara A, et al. Polymyalgia rheumatica and temporal arteritis: a retrospective analysis of prognostic features and different corticosteroid regimens (10 year survey of 29 patients). Ann Rheum Dis 1988; 46:733-9.

7 Paget SA, Healey JH, Williams-Russo $\mathrm{P}$, et al. Osteoporosis in steroid-treated patients with polymyalgia rheumatica and temporal arteritis: what is the magnitude and rate over 1 year. Arthritis Rheum 1992;35:S9.

8 Adhikary HP, Sells RA, Basu PK. Ocular complications of systemic steroid after renal transplantation and their association with HLA. Br f Ophthalmol 1982;66:290-1. 
9 Godel V, Feiler-Ofry V, Stein R. Systemic steroids and ocular fluid dynamics. I. Analysis of the sample as a whole. Influence of dosage a

10 Godel V, Feiler-Ofry V, Stein R. Systemic steroids and ocular fluid dynamics. II. Systemic versus topical steroids. Acta Ophthalmol 1972;50:664-76.

11 Urban RC, Cotlier E. Corticosteroid-induced cataract. Surv Ophthalmol 1986;31:102-10.

12 Hernandez C, Fernandez B, Ramos P, et al. Giant cell arteritis therapy: methotrexate as a steroid-sparing agent Arthritis Rheum 1991;34:S73.

13 Van der Veen MJ, Dinant HJ, van Booma-Frankfort C, et al. Can methotrexate be used as a steroid sparing agent in the treatment of polymyalgia rheumatica and giant cell arteritis? Ann Rheum Dis 1996;55:218-23.

14 Hunder GG, Bloch DA, Michel BA, et al. The American College of Rheumatology 1990 criteria for the classification of giant cell arteritis. Arthritis Rheum 1990;33:1122-8

15 Pelli DG, Robson JG, Wilkins AJ. The design of a new letter chart for measuring contrast sensitivity. Clin Vis Sci chart for measur

16 The Advanced Glaucoma Intervention Study Investigators. Advanced glaucoma intervention study. 2. Visual field testing scoring and reliability. Ophthalmology 1994;101:144555

17 Chylack LT, Leske M, Sperduto R, et al. Lens opacities classification system. Arch Ophthalmol 1988;106:330-4.

18 Leske MC, Chylack LT, Sperduto R, et al. Evaluation of lens opacities classification system. Arch Ophthalmol 1988; 106:327-9.

19 Kupersmith MJ. Neurovascular neuro-ophthalmology. Heidelberg: Springer-Verlag, 1993:211.

20 Huston KA, Hunder GG, Lie JT, et al. Temporal arteritis: a 25 year epidemiologic, clinical and pathologic study. Ann Intern Med 1978;188:162-7.

21 Hollenhorst RW, Brown JR, Wagener HP, et al. Neurologic aspects of temporal arteritis. Neurology 1960;10:490-8.

aspects of temporal arteritis. Neurology 1960;10:490-8.
22 Liu GT, Glaser JA, Schatz NA, et al. Visual morbidity in giant cell arteritis. Clinical characteristics and prognosis for giant cell arteritis. Clinical characteristics

23 Calamia KT, Hunder GG. Clinical manifestations of giant cell (temporal) arteritis. Clin Rheum Dis 1980;6:389-403.

24 Rosenfeld SI, Kosmorsky GS, Klingele TG, et al. Treatmen of temporal arteritis with ocular involvement. $\mathrm{Am} \mathcal{F} \mathrm{Med}$ 1986;80:143-5.
25 Thystrup J, Knudsen GM, Mogensen AM, et al. Atypical visual loss in giant cell arteritis. Acta Ophthalmol 1994;72: visual lo $759-64$.

26 Cohen DN. Temporal arteritis: improvement in visual prognsosis and management with repeat biopsies. Trans $\mathrm{Am}$ Acad 1973;77:74-85.

27 Aiello PD, Trautmann JC, McPhee TJ, et al. Visual prognosis in giant cell arteritis. Ophthalmology 1993;100:550-5.

28 Slavin M, Margolis AJ. Progressive anterior ischemic optic neuropathy due to giant cell arteritis despite high-dose intravenous corticosteroids. Arch Ophthalmol 1988;106: intraven

29 Beevers DG, Harpur JE, Turk KAD. Giant cell arteritis: the need for prolonged treatment. F Chron $\mathcal{F}$ Dis 1973;26:57184 .

30 Sorensen PS, Lorenzen I. [Giant-cell arteritis, temporal arteritis, and polymyalgia rheumatica.] [Danish] Ugescrift for Laeger 1975;137:1135-41.

31 Myles AB, Perera T, Ridley MG. Prevention of blindness in giant cell arteritis by cortciosteroid treatment. $\mathrm{Br} f$

32 Meli B. Landau K, Gloor BP. Die tucken der riesenzellarteriitis aus ophthalmologischer sicht. Schweiz Med Wochenschr 1996;126:1821-8.

33 Healey LA, Wilske KR. Manifestations of giant cell arteritis. Med Clin NA 1977;61:261-70.

34 Blumberg S, Giansiracusa DF, Docken WP, et al. Recurrence of temporal arteritis. clinical recurrence nine years after initial illness. $¥ A M A$ 1980;244:1713-14.

35 Cullen JF. Temporal arteritis occurrences of ocular complications seven years after diagnosis. $\mathrm{Br} \mathcal{F}$ Ophthalmol 1972;56:584-8.

36 Hamilton CR Jr, Shelley WM, Tumulty PA. Giant cell arteritis: including temporal arteritis and polymyalgia rheumatica. Medicine 1971;50:1-27.

37 Kyle V, Hazelamn BL. Treatment of polymyalgia rheumatica and giant cell arteritis. 1. steroid regimens in the first two months. Ann Rheum Dis 1989;48:658-61.

38 Faarvang KL, Pontoppidan Thyssen E. Giant cell arteritis: loss of vision during corticosteroid therapy. F Intern Med 1989;225:215-16.

39 Cumming RG, Mitchell P, Leeder SR. Use of inhaled corticosteroids and the risk of cataracts. $N$ Engl $\mathcal{F}$ Med 1997;337:8-14. 